Original article

\title{
Kaş Destinasyonunun Macera Turizmi Potansiyelinin Değerlendirilmesi
}

\section{Evaluation of Adventure Tourism Potential of Kaş Destination}

\author{
Iş1l Cankül (i) * \\ Institute of Social Sciences, Anadolu University, Eskişehir, Turkey
}

\begin{abstract}
Özet
Bu araştırmada Kaş’taki macera turizmini potansiyelinin değerlendirilmesi amaçlanmaktadır. Bu amaç doğrultusunda araştırmada macera turizmi konusunda bilgi sahibi ve deneyimli kişilerin görüşleri çerçevesinde Kaş'taki macera turizmi potansiyelini ortaya çıkarabilmek için nitel araştırma yöntemlerinden fenomenolojik araştırma türü tercih edilmiştir. Araştırmada olasılığa dayalı olmayan örnekleme tekniklerinden yargısal örnekleme tekniği kullanılmıştır. Bu kapsamda araştırmanın katılımcılarını Kaş destinasyonunda yer alan ve macera turizmi özelinde hizmet veren acentelerin sahipleri, yöneticileri, çalışanları, rehberleri ve dalış eğitmenleri oluşturmaktadır. Katılımcıların her biri yıllardır Kaş bölgesinde çalışmış ve süreci yakından gözlemleyecek kadar deneyime sahip alanında uzman ve profesyonel kişilerdir. Görüşmeler 2021 yılı Haziran ve Ağustos ayları içerisinde gerçekleştirilmiştir. Veri toplamak için yarı yapılandırılmış görüşme tekniği kullanılmıştır. Yarı yapılandırılmış görüşme tekniği kullanılarak elde edilen veriler içerik analizi ve betimsel analiz kullanılarak çözümlenmiştir. Elde edilen bulgular, Kaş’taki macera turizmi potansiyelinin, taşıdığı tüm coğrafi, tarihi ve kültürel cazibelerden dolayı oldukça yüksek olduğunu ancak bu potansiyelin doğru değerlendirilmeye intiyaç duyulduğu aksi halde Kaş'ın sahip olduğu bu büyük avantajların ciddi dezavantajlara yol açabileceğini göstermektedir.
\end{abstract}

Anahtar Kelimeler: Macera Turizmi, Macera Turisti, Kaş.

\begin{abstract}
In this research, it is aimed to evaluate the potential of adventure tourism in Kaş. For this purpose, in the research, phenomenological research type, one of the qualitative research methods, was preferred in order to reveal the adventure tourism potential in Kaş within the framework of the opinions of people who are knowledgeable and experienced in adventure tourism. Judgment sampling technique, which is one of the nonprobability sampling techniques, was used in the research. In this context, the participants of the research are the owners, managers, employees, guides and diving instructors of the agencies located in Kaş destination and serving specifically for adventure tourism. Each of the participants are experts and professionals in their fields who have worked in the Kaş region for years and have enough experience to observe the process closely. The interviews were held in June and August 2021. Semi-structured interview technique was used to collect data. The data obtained using the semistructured interview technique were analyzed using content analysis and descriptive analysis. The findings show that the adventure tourism potential in Kaş is quite high due to all the geographical, historical and cultural attractions it has, but this potential needs to be evaluated correctly, otherwise these great advantages of Kaş can lead to serious disadvantages.
\end{abstract}

\footnotetext{
* Corresponding author:

Işıl Cankül, Institute of Social Sciences, Anadolu University, Eskişehir, Turkey. Email: emecanisil@gmail.com
} 


\section{GíRIŞ̧}

Teknolojinin ve ekonominin gelişmesiyle birlikte belli bir sosyo-ekonomik konumda bulunan turistlerin de turizm alışkanlıklarının değiştiği söylenebilir. Bu durum kitle turizmi ve klasik deniz, kum, güneş tatil anlayışının hakim olduğu yerli ve yabancı turistleri "hayatında yeni bir deneyim yaşamak isteyen" turist anlayışına doğru götürmektedir. Farklı deneyimler yaşamak isteyen bu turist anlayışı ile birlikte alternatif turizm olarak da nitelendiren farklı turizm kolları gelişim göstermiş ve arz talep doğrultusunda yeni turizm türleri ortaya çıkmıştır. Bu turizm türlerinden biri de doğa turizmi başlığı altında yer edinen macera turizmidir.

Dünya Turizm Örgütü'ne göre dünyada doğa ve macera turizmindeki talep artış1 \%20-30'lara ulaşarak ciddi bir büyüme oranı elde edilmiştir. Doğa bazlı turizm hareketlerinin yarattı̆̆ı harcama 400 milyar, sadece macera turizmi harcamaları ise 263 milyar dolar olarak ölçülmüştür (Türsab, 2021). Bu verilerden de anlaşıldığı üzere dünyada turizm trendi macera turizmi alanında hızlı bir büyüme içerisinde olduğu gibi, Türkiye'de de macera turizmi giderek artan bir talep çeşitliliğine sahiptir. Türkiye, doğası, coğrafi değerleri, somut ve somut olmayan kültürel mirasları, tarihi ve mutfağıyla birlikte dünyanın en özel turizm cazibe merkezlerinden biri konumundadır. Türkiye coğrafi değerleri göz önüne alındığında birçok ekstrem spor dalında macera turizmi alanında değerlendirilmeyi bekleyen çok büyük bir potansiyele sahiptir. Macera turizmi, Türkiye'nin doğal kaynaklarını ve kültürel değerlerini alternatif bir bakış açısıyla sunarak, bu potansiyelin doğrudan açığa çıkmasına imkan tanımaktadır. (Garda, 2010: 236). Bu araştırmada Türkiye'nin en önemli turistik cazibe merkezlerinden olan Antalya'nın Kaş ilçesindeki macera turizmi potansiyeli araştırılmaktadır. Araştırma bölgesi için Kaş destinasyonunun seçilmesinin nedeni Kaş bölgesinde trekking, hiking, canyoning, tırmanış, kayak, rafting, yelken, yamaç paraşütü, bisiklet, dalış sporları, deniz kanosu, safari gibi birçok ekstrem sporun yapılabiliyor olması ve bu destinasyonun önemli bir kültürel mirasa ev sahipliği yapıyor olmasıdır.

\section{KAVRAMSAL ÇERÇEVE}

Bugünün tüketicileri, tüm tarihsel süreç değerlendirildiğinde her zamankinden daha fazla seçeneğe ve bu seçenekleri hayata geçirmek için çok çeşitli imkanlara sahiptir (Meyer ve Schwager 2007: 2). Tüketiciler çeşitli reklam ve pazarlama çalışmalarına karşı her geçen gün daha fazla bağışıklık kazanırken, ihtiyaç duydukları şey yeni bir deneyim yaşamalarını sağlayabilecek yaratıcı firsatlardır. 
Tüketicilerin bu tip ihtiyaçlarını fark eden işletmeler, onların ihtiyacını karşılayacak yaratıcı firsatlar sunarak çeşitli deneyim firsatları yaratmaya ve bunu sürdürmeye devam etmektedir. İşletmelerin yarattığı deneyim fırsatları, sadece bir ekonomik katkı değil, müşteride farklı anılar bırakan böylece işletmeye sadakat geliştiren bir ekonomik katkı olarak değerlendirilmektedir. (Gilmore ve Pine 2002: $5)$.

Uluslararası Deneyimsel Pazarlama Birliği (IXMA), globalleşen dünya pazarında, sadece müşterilerine, ihtiyaç duydukları doğru deneyimi sunabilen işletmelerin var olmaya devam edeceğini vurgulamaktadır. Tüm bu etkenler sonucunda deneyimsel pazarlama kavramı, müşteri memnuniyeti ve müşteri sadakatini sağlamak için öne çıkan önemli bir araç olarak karşımıza çıkmaktadır (Saltık, 2011: 28). Sundbo (2009: 431) ise deneyimsel pazarlamanın neden günümüzde bu kadar ön planda olduğunu; "toplumun yeni deneyim ihtiyacı, işletmelerin inovatif yaklaşımları ve teknoloji şeklinde açıklamaktadır.

Deneyimsel pazarlama kavramı, turistlerin yeni bir deneyim kazanmasıyla doğrudan ilişkilendirildiği için, yeni bir deneyim imkanı sunan alternatif turizm çeşitleriyle de direkt bir bağlantı içerisindedir. Alternatif turizm çeşitlerinden biri olan macera turizmi ise turistler tarafından doğrudan deneyimlenen bir turizm türü olduğu için deneyimsel pazarlama çerçevesinde incelenebilmektedir. Kanada Turizm Komisyonu (2001) yılında yaptığı açıklamada; macera turizmini "sıra dışı, özgün, uzak ve risk oranı yüksek destinasyonlarda gerçekleşen ve çeşitli risk seviyelerindeki aktivitelere eğilimli olan kişilerin yaptığı boş zaman aktivitesi olarak tanımlamaktadır.

Ryan, (2002:21) macera turistini; kendilerine yabancı bölgelerde, öz keşif ve kültürel zenginliği deneyimleyecekleri orijinal seyahatleri tercih eden kişiler olarak tanımlarken, macera turistlerinin diğer turist tiplerinden daha farklı davranış kalıplarına sahip olduklarını belirtmektedir. Lepp and Gibson (2008: 742) ise; macera turistlerinin genellikle fiziksel ve mental anlamda risk arayışında olduğunu ve bu mücadeleyi kazanmak istediklerinin altını çizmektedir. Bunun altında yatan nedenin ise kişisel gelişim, tecrübe ve öz saygı gibi değerler olduğunu söylemektedir.

Türkiye'nin en önemli turizm cazibe merkezlerinden biri olan Antalya'nın Kaş ilçesi Türkiye'nin güneyinde, Antalya şehir merkezine $254 \mathrm{~km}$ uzaklıkta yer almaktadır. Toplamda $2.231 \mathrm{~km}^{2}$ alan kaplayan Kaş, 2020'de yapılan nüfus sayımına göre ortalama 61 bin nüfusa sahiptir. Kaş'a karayolu ulaşımı vardır. Havayolu ulaşımı ise Muğla'nın Dalaman ilçesinden, oradan karayoluyla Kaş’a ulaşılmaktadır. Ulaşımı görece olarak uzak ve zor olmasına rağmen, önemli bir turistik cazibe noktası olmaya devam etmektedir. Kaş, yıllar içerisinde birtakım değişimler gösterse de mevcut özgün yapısını hala korumaktadır. Tipik Akdeniz ikliminin görüldüğü Kaş’ta yazları oldukça sıcak, kışları ise yumuşak ancak yağışlı geçmektedir (Kaş Belediyesi, 2021). 
Yerli ve yabancı turistler tarafından yoğun bir şekilde ziyaret edilen Kaş, tarihi dokusunun yanı sıra, macera turizmi için de özel bir bölgedir. Türkiye'nin en iyi dalış lokasyonlarından biri olan Kaş, 535 km’lik Likya Yolu yürüyüş parkurunun önemli bölümlerinden biri konumundadır. Ayrıca trekking, hiking, dalış sporları, deniz kanosu, coasteering, yamaç paraşütü, kite surfing, bisiklet turu, canyoning, jeep safari turları gibi diğer ekstrem sporlar için de sıklıkla tercih edilir niteliktedir. Ayrıca Kaş’ta macera turizmi hizmeti veren birçok outdoor tur acentesi bulunmaktadır (Kaş Belediyesi, 2021).

\section{YÖNTEM}

$\mathrm{Bu}$ çalışmada Kaş’taki macera turizmini potansiyelinin değerlendirilmesi amaçlanmaktadır. Bu amaç doğrultusunda araştırmada nitel araştırma nitel araştırma yöntemlerinden fenomenolojik araştırma türü kullanılmıştır. Fenomenolojik araştırma, belirli bir konu ile ilgili insanların düşüncelerini, duygularını, hislerini ifade etmesine imkan tanımaktadır (Rose, Beeby \& Parker, 1995:1124). Bu araştırmada macera turizmi konusunda bilgi sahibi ve deneyimli kişilerin görüşleri çerçevesinde Kaş’taki macera turizmi potansiyelini ortaya çıkarabilmek için fenomenolojik araştırma türü tercih edilmiştir.

Araştırmada olasıllğa dayalı olmayan örnekleme tekniklerinden yargısal örnekleme tekniği kullanılmıştır. Bu örneklemde, araştırmacı bireysel gözlemlerinden hareketle araştırma amacına uygun olduğunu düşündüğ̈̈ belirli özellikleri taşıyan kişileri seçmektedir (Gürbüz ve Şahin, 2006: 134). Bu kapsamda araştırmanın katılımcılarını Kaş destinasyonunda yer alan ve macera turizmi özelinde hizmet veren acentelerin sahipleri, yöneticileri, çalışanları, rehberleri ve dalış eğitmenleri oluşturmaktadır. Katılımcıların her biri yıllardır Kaş bölgesinde çalışmış ve süreci yakından gözlemleyecek kadar deneyime sahip alanında uzman ve profesyonel kişilerdir.

Görüşmeler 2021 y1lı Haziran ve Ağustos ayları içerisinde gerçekleştirilmiştir. Bu araştırma için yapılan görüşme sayısı toplamda onbeş adettir. Görüşme formları e-mail üzerinden gönderilmiş ve cevaplar e-mail yoluyla alınmıştır. Veri toplamak için yarı yapılandırılmış görüşme tekniği kullanılmıştır. Yarı yapılandırılmış görüş tekniğinin amacı görüşme konularının daha detaylı şekilde ele alınmasıdır. Görüşme soruları hazırlanırken konusunda uzman 1 akademisyenin görüşüne başvurulmuştur. Sorular detaylı incelenerek, bazı sorular değiştirilip düzenlenmiş ve sorular son haline gelmiştir. Görüşme formunda toplam beş soru yer almaktadır. Araştırma kapsamında katılımcıların görüşme detayları aşağıda yer alan Tablo 1'de gösterilmektedir. Tabloda acente isimlerine ve görüşülen kişilerin isimlerine yer verilmemiş, kişiler için kod numaraları kullanılmıştır. 
Tablo 1. Görüşülen kişilerin özellikleri ve görüşme detayları

\begin{tabular}{ccccc}
\hline $\begin{array}{c}\text { Görüssülen } \\
\text { Kişi }\end{array}$ & $\begin{array}{c}\text { Deneyim } \\
\text { Süresi }\end{array}$ & $\begin{array}{c}\text { Görüşme } \\
\text { Tarihi }\end{array}$ & Görüşülen Kişi & Görüşme Yeri \\
\hline G1 & 8 & 25.06 .2021 & Acenta yöneticisi & E-mail \\
\hline G 2 & 12 & 25.06 .2021 & Rehber & E-mail \\
\hline G 3 & 3 & 27.06 .2021 & Rehber & E-mail \\
\hline G 4 & 17 & 27.06 .2021 & Acenta sahibi & E-mail \\
\hline G 5 & 22 & 10.07 .2021 & Acenta sahibi & E-mail \\
\hline G 6 & 6 & 11.07 .2021 & Acenta çalışanı & E-mail \\
\hline G 7 & 6 & 11.07 .2021 & Rehber & E-mail \\
\hline G 8 & 23 & 12.07 .2021 & Acenta sahibi & E-mail \\
\hline G 9 & 15 & 02.08 .2021 & Acenta yöneticisi & E-mail \\
\hline G 10 & 12 & 02.08 .2021 & Acenta yöneticisi & E-mail \\
\hline G 11 & 3 & 04.08 .2021 & Rehber & E-mail \\
\hline G 12 & 5 & 05.08 .2021 & Acenta çalışanı & E-mail \\
\hline G 13 & 7 & 12.08 .2021 & Rehber & E-mail \\
\hline G 14 & 11 & 13.08 .2021 & Dalış Ĕgitmeni & E-mail \\
\hline G 15 & 10 & 13.08 .2021 & Dalış Ĕgitmeni & E-mail \\
\hline
\end{tabular}

Acentelerin yöneticileri, çalışanları, rehberleri ve dalış eğitmenleri ile yapılan görüşmeler çözümlenerek veriler kodlanmış ve analiz edilmiştir. E-mail yoluyla elde edilen görüşme formlarının deşifresi yapılmıştır. Yarı yapılandırılmış görüşme tekniği kullanılarak elde edilen veriler içerik analizi ve betimsel analiz kullanılarak çözümlenmiştir. Çalışmanın geçerliliğini sağlamak amacıyla kullanılan yöntemlerden birisi ayrıntılı betimleme ve uzman incelemesidir (Creswell, 2014). Bu kapsamda araştırılan konuya uygun yöntem seçilerek, görüşme soruları hazırlandıktan sonra konuyla ve yöntemle ilgili uzman kişilerden görüşler alınmış, gerekli düzenlemeler yapılmış, verilerin incelenmesi ve kontrol edilebilmesi için görüşme metinlerine ilişkin alıntılara (sonuçlara nasıl ulaşıldığını göstermesi bakımından) metin içerisinde yer verilmiştir.

\section{BULGULAR}

Kaş’taki macera turizmi potansiyelini ölçümlemek üzere gerçekleştirilen yarı yapılandırılmış görüşme sorularına verilen cevaplar tablolarda ana tema, kategori ve kodlar şeklinde belirtilmiştir. Tablolarda belirtilen ana tema başlığı, sorulan soruların ana fikrini belirtirken, kategori başlığı verilen cevap gruplarını nitelendirmektedir. Kod başlığı ise verine cevapların hangi anahtar kelimelerle yanıtlandığını göstermektedir. Bu bağlamda tabloların yorumu doğrudan alıntılar ile desteklenmiştir. Tablolar yorumlanırken çarpıcı ifadelere yer verilmiş, bu cevaplardan yola çıkarak tablolar son haline getirilmiştir. 


\section{Turizm Potansiyeli ile Ilgili Görüş̧ler}

Görüşülen kişilere sorulan "Kaş’taki macera turizmi potansiyelini nasıl değerlendiriyorsunuz?" sorusuna verilen yanitların analizi sonucunda "turizm potansiyeli" adı altında ana tema ve bu ana tema altında “yüksek ve yeterli” ve "yetersiz” olmak üzere iki alt tema belirlenmiştir. (Tablo 2).

Tablo 2. Turizm potansiyeli

\begin{tabular}{lll}
\hline Ana Tema & Kategori & Kod \\
\hline \multirow{2}{*}{ Turizm potansiyeli } & Yüksek ve yeterli & $\begin{array}{l}\text { Yüksek potansiyel, kalker arazi, tarih, özgün, likya } \\
\text { yolu, biyolojik çeşitlilik }\end{array}$ \\
\cline { 2 - 3 } & Yetersiz & $\begin{array}{l}\text { İniş pisti yok, on yıldır ciddi bir düşüş } \\
\text { yaşanmaktadır, kalabalık, bozulan doğa, yetersiz } \\
\text { aktivite }\end{array}$ \\
\hline
\end{tabular}

Görüşülen kişilerin bazılarının öne çıkan/dikkat çeken ifadeleri şu şekildedir;

“Kaş’ın turizm olanaklarının geç algılanması onun aslında şansı... Ulaşılması zor olduğundan dolayı tanınmamış ve bu sayede kitle turizminden uzak kalabilmiş olmast ve elindeki doğal ve kültürel değerler sayesinde doğa-macera-keşif turizminde değerlendirilebilecek imkanları bol. Doğu Akdeniz sualtı dünyasının Akdeniz-Kızıldeniz karışımı dinamik karakteriyle, halen tamamı keşfedilmemiş veya çalışılmamış antik yerleşimleriyle, yoğun insan kullanımına açılmamış Toros 'ların issız ve yabani ortamları ve dolayısıyla her ortamdaki zengin biyolojik çeşitlilik doğru değerlendirilebilirse yüksek potansiyel var."(K15)

“Kaş’ta macera turizmi geçtiğimiz 10 yll içerisinde çok fazla düşüş yaşadı. Turistlerin sınıfı değişti. Yabancı turistler doğa sporu taraftarı iken Türk turistler teknede yatmayı tercih ediyor. Yabancı turist artık gelmiyor maalesef. " (K7)

\section{Turizm Sektörünün Yıllar İçindeki Değişimi}

Görüşülen kişilere sorulan "Kaş’taki macera turizminin yıllar içerisindeki değişimini nasıl değerlendiriyorsunuz?" sorusuna verilen yanıtların analizi sonucunda "değişim” adı altında ana tema ve bu ana tema altında "turist profili" "turist sayısı" ve "çevre" olmak üzere üç alt tema belirlenmiştir. (Tablo 3).

Tablo 3. Yıllar İçindeki Değişim

\begin{tabular}{lll}
\hline Ana Tema & Kategori & Kod \\
\hline \multirow{3}{*}{ Değişim } & Turist Profili & Villa tatilcileri, plaj tatilcisi \\
\cline { 2 - 3 } & Turist Sayısı & Kalabalık, azalan yabancı turist \\
\cline { 2 - 3 } & Çevre & Huzlı yapılaşma, bozulan doğa \\
\hline
\end{tabular}


Görüşülen kişilerin bazılarının öne çıkan/dikkat çeken ifadeleri şu şekildedir;

"Ülkede yaşanan stres unsurları nedeniyle turizm genel olarak düşmekle birlikte, 2016 öncesi daha çok yurt dışı misafirlere hizmet veriyordu Kaş. Outdoor aktiviteler için Türk misafirler çok istekli, ilgili olmadiğından hacmi giderek düşüyor." (K1)

“Olumsuz yönde gelişiyor, bölgenin doğası bozuldukça cazibesi kayboluyor” (K13)

“Kaş'a gelen turist profiliyle bağlantılı olarak tur profilleri de değişti. Maalesef bu olumsuz bir değişim. Eskiden daha çok yabancı turist haftalık turlar alıp Kaş'a gelirdi. Kanyon, paraşüt gibi turlar çok popülerdi. Çoğu tur için katılımı sayısı oldukça düştü. Daha çok plaj tatili veya villa tatilcisi şu anki ziyaretçi profili. (K8)

\section{Macera Turizmi Kapsamında Verilen Hizmetler}

Görüşülen kişilere sorulan "Macera turizmi alanında turistlerin beklentilerini karşılayan ne tür bir deneyim veya deneyimler sunuyorsunuz?" sorusuna verilen yanttların analizi sonucunda "hizmetler" adı altında ana tema ve bu ana tema altında "tüplü dalış", "su sporları" ve "outdoor sporlar" olmak üzere üç alt tema belirlenmiştir. (Tablo 4).

Tablo 4. Hizmetler

\begin{tabular}{lll}
\hline Ana Tema & Kategori & Kod \\
\hline \multirow{3}{*}{ Hizmetler } & Tüplü dalış & Sertifika eğitimleri, deneme dalışları \\
\cline { 2 - 3 } & Su sporları & Deniz kanosu, coasteering, surf \\
\cline { 2 - 3 } & Outdoor sporlar & $\begin{array}{l}\text { Trekking, hiking, dağ bisikleti, yamaç } \\
\text { paraşütü, kuş gözlemi, botanik turlar }\end{array}$ \\
\hline
\end{tabular}

Görüşülen kişilerin bazılarının öne çıkan/dikkat çeken ifadeleri şu şekildedir;

"Yabancı turistler için kendi tasarladıkları turları dahi yapabiliyoruz. Dalış, trekking, mtb turu, safari, kanyoning, deniz kanosu, yüksek parkur hiking, paragliding vs"(K9)

"Acentemiz kıyı tırmanışı, kuş gözlem, botanik turlarl, sidemount gibi çok özgün turlar yapmaktadır. Rehberlerimiz yıllardır bizimle çalışmaktadır. Güvenlik ve müşteri memnuniyeti her zaman ön plandadır. Cankurtaranlık ve IDC gibi eğitimler de bünyemizde gerçekleştirilmektedir" (K8)

\section{Macera Turizminin Gelişimi}

Görüşülen kişilere sorulan "Kaş’taki macera turizmini geliştirmek için neler yapılabilir?" sorusuna verilen yanıtların analizi sonucunda "gelişim" adı altında ana tema ve bu ana tema altında "pazarlama", "politika” ve "inovatif fikirler” olmak üzere üç alt tema belirlenmiştir. (Tablo 5). 
Tablo 5. Gelişim

\begin{tabular}{lll}
\hline Ana Tema & Kategori & Kod \\
\hline \multirow{2}{*}{ Gelişim } & Pazarlama & İmaj, reklam, marka \\
\cline { 2 - 3 } & Politika & $\begin{array}{l}\text { Şehir düzenlemesi, altyapı destekleri, yerel } \\
\text { yöneticiler, hükümet desteği, yasal } \\
\text { düzenlemeler }\end{array}$ \\
\cline { 2 - 3 } & İnovatif fikirler & $\begin{array}{l}\text { Dört mevsim kaş, yeni aktiviteler, personel } \\
\text { eğitimi, sürdürülebilir turizm yaklaşımı }\end{array}$ \\
\hline
\end{tabular}

Görüşülen kişilerin bazılarının öne çıkan/dikkat çeken ifadeleri şu şekildedir;

“Kaş’ın özgün kimliği korunmalı ve şehir düzenlenmesi yapılmalı. 4 mevsim turizme çok uygun olan Kaş'ın sadece yaz tatili değil, 4 mevsim turizm planlanması yapılmalı” (K6)

Bu aslında tüm Kaş halkıyla alakalı bir durum. Kaş'ın gelişsimi artık dezavantaja dönüştü. Halkın konaklamaya pozitif bakması lazım. Daha fazla outdoor iletişim çalışmalı yapılmalı. Bu anlamda yerel yöneticilerin sözü çok önemli. Her yeri buna göre dizayn etmeliler. Dolayıslyla hükümetin çok daha titiz, organize hareket etmesi ve turizmi teşvik etmesi gerekiyor. Doğa, sadece parkurlara ve saat dilimlerine sikıştırılmamalı. Macera turizmi rahat bir organizasyonla gerçekleştirilmeli" (K13)

\section{SONUÇ}

Araştırma sonucunda, Kaş’taki macera turizmi potansiyeli, taşıdığı tüm coğrafi, tarihi ve kültürel cazibelerden dolayı oldukça yüksek olsa da, bu potansiyelin doğru değerlendirilmeye ihtiyaç duyulduğu aksi halde Kaş'ın sahip olduğu bu büyük avantajların ciddi dezavantajlara yol açabileceği görülmektedir.

Mevcut durumda, Kaş’taki macera turizminin yıllar içerisinde gerilemeye başladığı belirlenmiş; turizmin gelişimi fazla birikim ve uzmanlık alanı gerektirmeyen, daha çok eğlence sektörüne yapılan yatırımlarla hızlı tüketilebilen bir hale dönüştügü tespit edilmiştir. Tam olarak bir kitle turizminden bahsedilmese de, yine kalabalık sayılabilecek gruplara yönelik yapılan ye-iç tekne turları, ye-iç-1slan jeep safari vb. aktivitelerle macera turizminin yerini hızlı tüketim etkinliklerine bırakmıştır. Bu duruma paralel olarak macera turizmine yönelen acente ve profesyonel çalışanların sayılarının azaldığı ve macera turizmi hizmeti veren kişilerin azınlıkta olduğu ortaya çıkmıştır. Bunun yanında acente ve rehberlik hizmeti vermeye devam eden kişilerin macera turizmi kapsamında ağırlıklı olarak tüplü dalış, deniz kanosu, hiking, bisiklet, jeep safari turları, kuş gözlem, botanik ve keşif yürüyüşleri, Likya Yolu yürüyüşleri alanlarında hizmet verdiği saptanmıştır.

Kaş'taki macera turizmini geliştirmek için ilk önce Türkiye'nin imajının geliştirilmesi, Kaş'ın doğal ve tarihi yapısının korunması ve bu özelliklerden sürdürülebilir şekilde yararlanılması, doğaya zarar veren projelere izin verilmemesi gerektiği belirlenmiştir. Bunun yanında doğal tarım alanlarını 
bozan imar projelerinin önlenmesi, maden ve taş ocaklarının artmasının engellenmesi, karasal ve denizel koruma alanlarının artırılması ve paydaşların sürdürülebilir kullanımına açık olarak yönetilmesi gerekmektedir. Ayrıca macera turizmine yönelik turizm kitlelerinin bölgeyi tercih etmesini sağlayacak, doğaya ve bölgenin kültürel hayatına yönelik yaya ve bisiklet yolu, yaz dönemlerinde artan kapasiteye yönelik altyapı çalışmaları gibi kentsel yatırımlara öncelik verilmelidir.

\section{KAYNAKÇA}

Cresswell, J. W. (2014). Research Design-Qualitative, Quantitative, snd Mixeed Methods Approaches (Fourth Edition), New Delhi-Sage.

Garda, B. (2010). Macera turizmi pazarlaması: Antalya yöresine gelen turistlerin macera turizmine yönelik eğilimleri üzerine bir araştırma. Selçuk Üniversitesi Sosyal Bilimler Enstitüsü, Üretim Yönetimi ve Pazarlama Bilim Dalı, Konya.

Gilmore, J., and Pine, J. (2002). Customer Experience Places: The New Offering Frontier, Strategy \& Leadership, 30(4), 4-11.

Gürbüz, S., and Şahin, F. (2016). Sosyal Bilimlerde Araştırma Yöntemleri. Ankara: Seçkin Yayıncıllk.

Kanada Turizm Komisyonu (2001). "Outdoor Tourism: An Industry Profile and Resource Guide" The Canadian Tourism Human Resources Council Ottawa.

Kaş Belediyesi. (2021). https://www.kas.bel.tr/

Lepp, A. and Gibson, H. (2008). Sensation seeking and tourism: Tourist role, perception of risk and destination choice, Tourism Management 29(4), 740-750.

Meyer, C., and Schwager, A. (2007). Understanding Customer Experience, Harvard Business Review, $85(2), 116-126$.

Saltık, I. A. (2011). Turizm Sektöründe Deneyimsel Pazarlama Ve Tüketici Davranışları Üzerine Etkisi. Yayınlanmamış Yüksek Lisans Tezi, Muğla Sıtkı Koçman Üniversitesi Sosyal Bilimler Enstitüsü, Muğla.

Sundbo, J.(2009). Innovation in the Experience Economy: A Taxonomy of Innovation Organisations, The Service Industries Journal, 29(4), 431-455.

Ryan, C. (2002). Equity, management, power sharing and sustainabilityFissues of the new Tourism, Tourism Management,23(1),17-26.

Rose, P., Beeby, J., and Parker, D. (1995). Academic rigour in the lived experience of researchers using phenomenological methods in nursing in nursing. Journal of Advanced Nursing, 21(6), 1123-1129.

Türkiye Seyahat Acentaları Birliği (TÜRSAB). (2021). TÜRSAB Doğa ve Macera Turizmi Raporu, https://www.tursab.org.tr/dosya/12896/tursab-dogamaceraturizmi_12896_5091237.pdf. 